\title{
MONITORAMENTO DE EROSÃO HÍDRICA EM AMBIENTE DE CERRADO, UBERLÂNDIA - MG
}

\author{
Anna Carolina Barcelos ${ }^{(\mathrm{a})}$, Vinícius de Oliveira Maruschi ${ }^{(\mathrm{b})}$ \\ (a) Instituto de Geografia/Universidade Federal de Uberlândia, barceloscarolina @ hotmail.com \\ (b) Instituto de Geografia/Universidade Federal de Uberlândia, vinicius.maruschi@ufu.br
}

\section{EIXO: SISTEMAS GEOMORFOLÓGICOS: ESTRUTURA, DINÂMICA E PROCESSOS}

\begin{abstract}
Resumo
As áreas de cerrado sofreram muito com os processos de ocupação que ocorreram de forma desenfreada desde a vinda dos primeiros colonizadores em busca dos seus recursos naturais, alguns estudos indicam que até o ano de 2002 o cerrado havia perdido consideravelmente sua área original, sendo modificado cada vez mais pela ação dos processos erosivos. O trabalho em questão foi desenvolvido na Fazenda Experimental do Glória, esta se encontra no município de Uberlândia - MG, e tem como objetivo avaliar o comportamento da erosão sobre duas parcelas experimentais em ambiente de cerrado. Para isso foi levado em consideração à coleta semanal de amostras de cada parcela obtendo dados de precipitação, escoamento superficial e produção de sedimento. $\mathrm{O}$ monitoramento foi realizado em duas etapas, apresentando resultados distintos, devido ao crescimento da vegetação nas parcelas, contribuindo para a diminuição da perda de solo e do escoamento superficial.
\end{abstract}

Palavras chave: Cerrado; Erosão; Parcelas Experimentais;

\begin{abstract}
The savanna areas suffered greatly from the occupation processes that occurred unbridled since the arrival of the first settlers in search of its natural resources, some studies indicate that by the year 2002 the savanna had lost considerably its original area, and modified increasingly by the action of erosion. The study in question was developed in the Experimental Farm of Gloria hat is the county of Uberlândia - MG, and aims to evaluate the behavior of erosion on two experimental plots in savanna environment. For this was taken into account the weekly sampling of each plot where were obtained rainfall data, runoff and sediment production. The monitoring was conducted in two stages, showing different results, due to the vegetation growth in the plots, contributing to the reduction of soil loss and runoff.
\end{abstract}

Keywords: Savanna; erosion; experimental plots.

\section{Introdução}

O Cerrado brasileiro engloba cerca de 2,04 milhões de quilômetros quadrados, caracterizando-se em torno de $22 \%$ do território nacional, é o segundo maior bioma do país ficando atrás apenas da Amazônia (SHIKI, 1997; SANO \& FERREIRA, 2005; KLINK \& MACHADO, 2005; SANTOS ET AL, 2010). Algumas estimativas indicam que até o ano de 2002 o Cerrado havia perdido 54,9\% de sua área original (MACHADO ET AL., 2004), sendo modificado cada vez mais pelas transformações de suas paisagens, 
por conseguinte intensificando os processos erosivos. A ocupação das áreas de cerrado aconteceu por volta do século XVIII, pois os recursos naturais eram de grande interesse para os homens que buscavam ouro, pedras preciosas e índios, no entanto não se pensava nos impactos ambientais que poderiam surgir após a utilização de grande parte desses recursos sem a devida preocupação. Foi então com a criação do projeto de colonização nos Cerrados e dos programas Polocentro e Proceder na década de 70 que deu início novamente a uma intensa ocupação voltada agora para a colonização e modernização agrícola (BACCARO, 2007; SHIKI, 1997).

Dessa forma, essas áreas sofreram novamente com o processo de ocupação agora mais profundo e predatório, que hoje são percebidos facilmente com os diversos problemas encontrados nas áreas de cerrado, como a devastação da vegetação natural, nos recursos hídricos, nos assoreamentos dos fundos de vale e na erosão dos solos. Para minimizar esses impactos faz-se necessário o estudo da dinâmica de vertentes, não apenas para compreender a evolução da paisagem geográfica, mas da mesma forma para desenvolver o controle dos processos erosivos que são intensificados pelas ações antrópicas no meio natural (BACCARO, 2007). No Brasil o domínio dos cerrados tem seu comportamento climático marcado pelos meses secos sendo de cinco a seis meses contrapondo-se aos meses mais chuvosos que vão de seis ou sete meses. A umidade do ar é relativa nos meses secos e chuvosos, pois nos meses secos atinge de 38 a $40 \%$ de umidade e nos meses chuvosos a umidade aumenta significativamente para 95 a $97 \%$ (AB'SÁBER, 2003).

A chuva é um dos elementos climáticos de maior influência em nosso país na erosão dos solos. Conhecida como erosão hídrica e sendo mais importante que a erosão causada pelos ventos, ocorre em duas fases, à primeira marcada pela desagregação seguida do transporte, a desagregação é gerada pelo impacto das gotas da chuva e também pela água que escoa na superfície. A ação das gotas de chuva pode ser considerada direta ou indireta, de forma direta as partículas do solo movimentam-se para baixo da vertente e na forma indireta a ação das gotas auxiliam na selagem dos poros superficiais, consequentemente reduz a infiltração e incentiva o escoamento superficial. Quando o solo se encontra desprovido de vegetação o impacto das gotas de água da chuva faz com que seu impacto desagregue as partículas do solo, sendo o início para a erosão, fazendo com que esse solo fique cada vez mais suscetível ao arraste mecânico do escoamento superficial da água (LEPSCH, 1976; GUERRA, A. T. 1999; BIGARELLA ET AL, 2003; DECHEN, 2004; MAFRA, A. L. 2012.).

Neste sentido, ao atingir a superfície do solo a água da chuva, pode escoar na superfície, em subsuperfície e subterraneamente. O tipo de escoamento depende da combinação de diversos fatores, como as condições climáticas, a declividade do terreno, natureza do solo, condições bióticas e edafológicas, as atividades antrópicas e o manejo do solo, são necessários para definir o predomínio, a importância e a tendência 
evolutiva dos sistemas de escoamento (POPOLIZIO, 1975 APUD BIGARELLA ET AL., 2003; LEPSCH, 1976; BIGARELLA ET AL, 2003). Sabe-se que o escoamento superficial (runoff) pode transcorrer em diversas formas sendo essas, o escoamento laminar ou em lençol (sheet wash), escoamento em filetes (rill wash), torrente em lençol (sheet flood), escoamento em ravina (gullying) e torrente canalizada (stream flood). (BORK \& ROHDENBURG, 1979 APUD BIGARELLA ET AL, 2003).

A atuação erosiva nas vertentes resulta a partir do poder erosivo da chuva, da erosividade do escoamento, fluxo de massas de solo, da friabilidade do solo ou da rocha. São vários os fatores que influenciam na erosividade, sendo eles, a intensidade da água da chuva, capacidade de infiltração da superfície, propriedades físicas e químicas do solo e a vegetação. A ação dos processos erosivos em solos arenosos e argilosos difere minimamente, pois nos solos arenosos a permeabilidade é extremamente alta, mas a coesão entre as partículas de areia é fraca, propiciando sua grande erodibilidade, já nos solos argilosos como exemplo nos latossolos são altamente permeáveis devido a sua estrutura que facilita a infiltração da água, mas suas partículas conseguem se agregar formando "falsos grãos de areia", gerando uma coesão muito fraca de suas partículas e propiciando uma erodibilidade alta (BIGARELLA ET AL., 2003).

Por conseguinte, o estudo em questão dará continuidade à avaliação qualitativa e quantitativa do comportamento da erosão hídrica sobre duas parcelas experimentais, iniciada por Barcelos (2016). No entanto, abordaremos o período que abarca os meses de fevereiro a abril de 2015 da pesquisa, tendo como objetivo central a análise dos parâmetros: precipitação semanal, escoamento superficial e produção de sedimento, visando obter resultados a respeito das mudanças nos processos geomorfológicos no espaço analisado.

\section{Fundamentação Teórica}

\subsection{Processos Erosivos}

Para Thornes (1980) os processos erosivos básicos possuem mecanismos que variam de acordo com o tempo e o espaço, fazendo com que a erosão aconteça desde o instante em que as forças que deslocam e transportam os materiais ultrapassam aquelas que tendem a opor a remoção. Esses processos erosivos básicos possuem uma relevância essencial para que se possa compreender como surge a erosão e quais são os seus efeitos (GUERRA, 2013).

Segundo Hasset e Banwart (1992 APUD GUERRA; JORGE, 2012), a forma mais comum de erosão é gerada pela ação da água, sendo essa a de maior distribuição espacial na superfície terrestre. Esse tipo de erosão dispõe de duas etapas, a primeira constitui-se pela remoção (detachment) das partículas do solo, 
podendo formar crostas em seu topo, a segunda etapa é caracterizada pelo deslocamento das partículas da primeira etapa na superfície do solo.

O splash tem papel fundamental na origem dos processos erosivos, pois organiza as partículas que estruturam o solo, para posteriormente serem carreadas pelo escoamento superficial. A organização das partículas se dá pela ruptura dos agregados, fragmentando-os em volumes menores e também pela ação transportadora que o splash ocasiona nas partículas dos solos. Esses agregados preenchem os poros da superfície do solo, promovendo com isso a selagem e redução da porosidade, favorecendo o aumento do escoamento das águas (GUERRA E GUERRA, 1997).

De acordo com Mafra (2012), a erosão resultante da chuva equivale fundamentalmente em uma ordem de matéria e energia propiciadas por uma instabilidade no sistema água - solo - cobertura vegetal, resultando em uma contínua perda de solo. O papel da cobertura vegetal nesse momento é fundamental para a manutenção do ciclo da água, pois protege o solo contra o impacto das gotas das chuvas. Auxilia também com a ação das suas raízes no aumento da porosidade e na permeabilidade do solo, reduzindo o escoamento superficial e mantendo a sua umidade e fertilidade através da presença de matéria orgânica (BELTRAME, 1994).

\subsection{A influência do Escoamento Superficial na produção de sedimento}

O solo possui características físicas, como textura, porosidade e profundidade que induzem de modo direto na capacidade de infiltração da água da chuva e na velocidade do escoamento superficial, afetando os processos erosivos (BELTRAME, 1994). A função do escoamento superficial está diretamente ligada à dinâmica da bacia hidrográfica a qual atua, determinando o fluxo da água da chuva que infiltrará no solo, propiciando o surgimento de nascentes e o fornecimento de água para os lençóis freáticos, ou que escoaram pela superfície da encosta para as áreas mais baixas do terreno (BARRELLA, 2001).

Nessa perspectiva, a intensidade do escoamento superficial depende das diferentes características do relevo, das condições climáticas e da capacidade protetora da vegetação, podendo sofrer variações de acordo com cada lugar. Magalhães (1995) aponta que em superfície, a erosão depende da ação das precipitações e do escoamento superficial difuso. O escoamento é função da declividade do terreno e das condições climáticas. O poder erosivo da água depende da densidade e velocidade do escoamento, da espessura da lâmina de água, da inclinação e comprimento da vertente, e da presença de vegetação.

Sendo assim segundo Guerra \& Guerra (1997), o escoamento superficial tem início quando o solo em princípio torna-se saturado, consequentemente a superfície desse solo atinge a capacidade de infiltração máxima não conseguindo absorver mais água. Apontam também que solos que não possuem cobertura 
vegetal, estão susceptíveis ao início do escoamento superficial levando a ocorrer à produção de sedimentos, sendo causa da origem de processos erosivos, tais como, sulcos, ravinas e voçorocas.

Segundo Baccaro (2007), o Cerrado em sua extensão apresenta um caráter climático extremamente marcante na evolução e dinâmica do escoamento superficial pluvial, sendo esse, o longo período de estiagem, de três a cinco meses (maio a setembro), deixando o solo exposto, ressecado e fendilhado. Em um estudo feito por Baccaro (1999) em ambiente de cerrado da região do Triângulo Mineiro, constatou-se que no início da estação chuvosa, a dinâmica do escoamento superficial e a do material em suspensão está diretamente ligada com a distribuição e comportamento das chuvas, essas sendo determinantes para obtenção do volume de escoamento e quantidade do material em suspensão.

Para Guerra e Guerra (1997, p.243) "a produção de sedimentos resulta da erosão de material e o consequente transporte desse material, que vem a ser depositado em uma área mais deprimida, em relação à área fonte”. Deste modo, é possível observar que as condições climáticas, a declividade do terreno e a falta de cobertura vegetal em determinado local podem favorecer a erosão do solo a partir do aumento do escoamento superficial e da produção de sedimento.

\section{Materiais e Métodos}

\subsection{Caracterização da área de estudo}

A escolha da área de estudo levou em consideração localização e as parcelas experimentais já existentes na área para a realização da pesquisa, a mesma foi desenvolvida pelo Laboratório de Geomorfologia e erosão dos solos da Universidade Federal de Uberlândia, que buscou obter mais prática em sua pesquisa através do trabalho de campo, com o apoio do monitoramento do experimento e do levantamento de dados semanais dos parâmetros utilizados nesse estudo.

A pesquisa foi realizada na Fazenda Experimental do Glória, nas coordenadas geográficas de 1856'56" de latitude Sul e 48 $12^{\prime} 21^{\prime \prime}$ de longitude Oeste de Greenwich, a sudeste do município de Uberlândia - MG a uma altitude de 919 metros acima do nível do mar, presentes na bacia hidrográfica do Córrego do Glória, afluente da margem direita do Rio Uberabinha e subafluente do rio Araguari. A área está situada sob Domínio dos Planaltos e na Chapada da Bacia Sedimentar do Paraná, com tabular e levemente ondulado. A formação geológica predominante é a Formação Marília, em área de contato entre o Grupo São Bento e o Grupo Bauru, ocorrendo afloramento de basaltos e arenitos, os solos presentes são ácidos e pouco férteis do tipo Latossolo Vermelho com textura argilo-arenosa (BEZERRA, 2006).

De acordo com Silva (2010), o clima da região é caracterizado por clima tropical, sendo Aw segundo a classificação de Köppen. Apresenta inverno seco e verão chuvoso, com temperatura média anual de $22^{\circ} \mathrm{C}$, 
variando entre médias de $24^{\circ} \mathrm{C}$ nos meses de Outubro a Março (meses mais quentes) e $18^{\circ} \mathrm{C}$ nos meses de Junho e Julho (meses mais frios). Em relação à precipitação, a variação se da entre $1300 \mathrm{~mm} / \mathrm{ano}$ a 1700 $\mathrm{mm} /$ ano. As estações, chuvosa e seca, duram cerca de seis meses cada, sendo que "este processo característico ocorre devido ao deslocamento da área de influência das massas de ar que atuam sobre a região, que são elas: Massa Equatorial Continental, a Tropical Atlântica e a Massa de Ar Polar." (ALVES, 2007).

\subsection{Materiais e Métodos}

A pesquisa está fundamentada no monitoramento e coleta de dados provenientes de duas parcelas experimentais, localizadas na Fazenda Experimental do Glória no município de Uberlândia - MG (Figura 2). As parcelas experimentais onde foram aplicadas as atividades do presente trabalho possuem $10 \mathrm{~m}^{2}$ de extensão, cercadas por barreiras de alvenaria, conectadas as calhas coletoras e aos galões com capacidade de 250 litros, declividade de $12^{\circ}$, e situadas na vertente esquerda do Córrego do Glória (Figura 1).

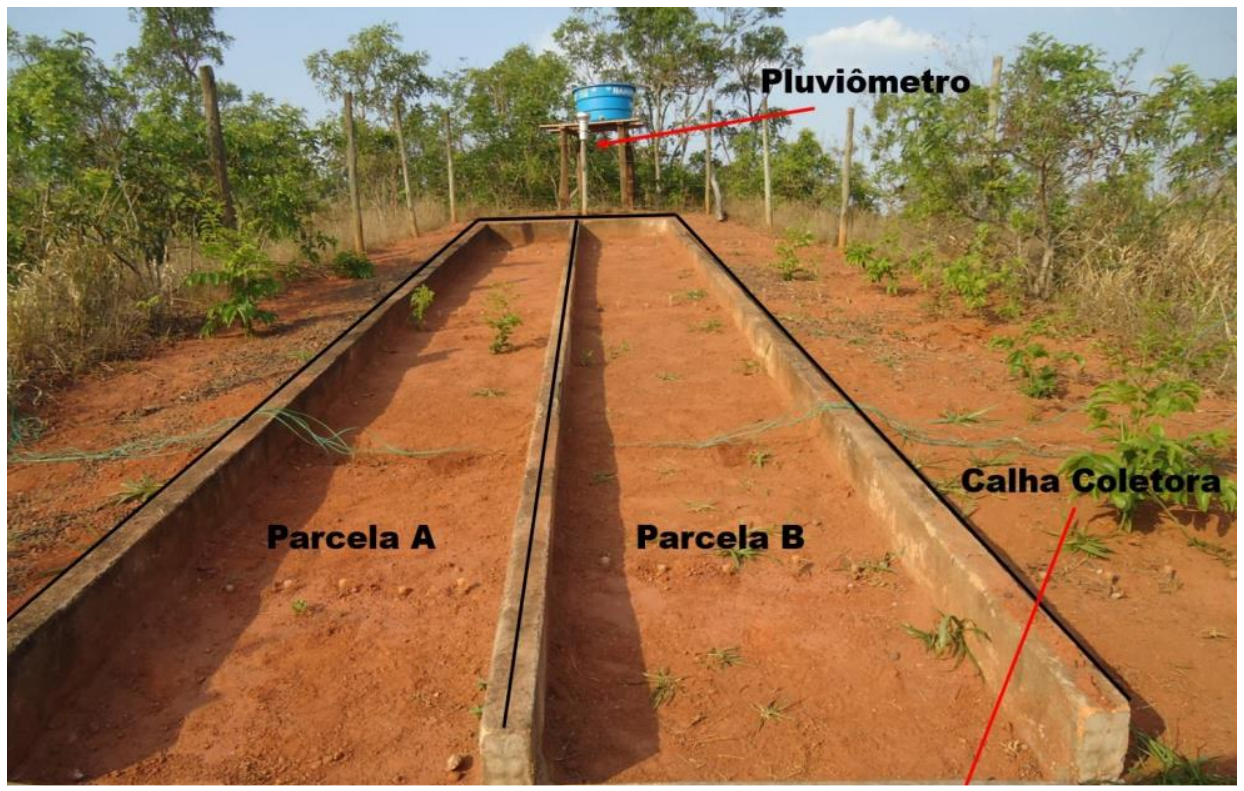

Figura 1: Estrutura das parcelas experimentais

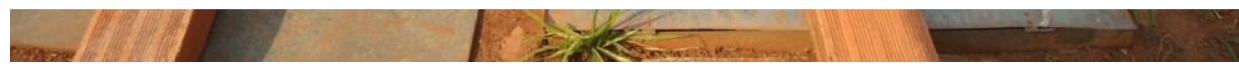



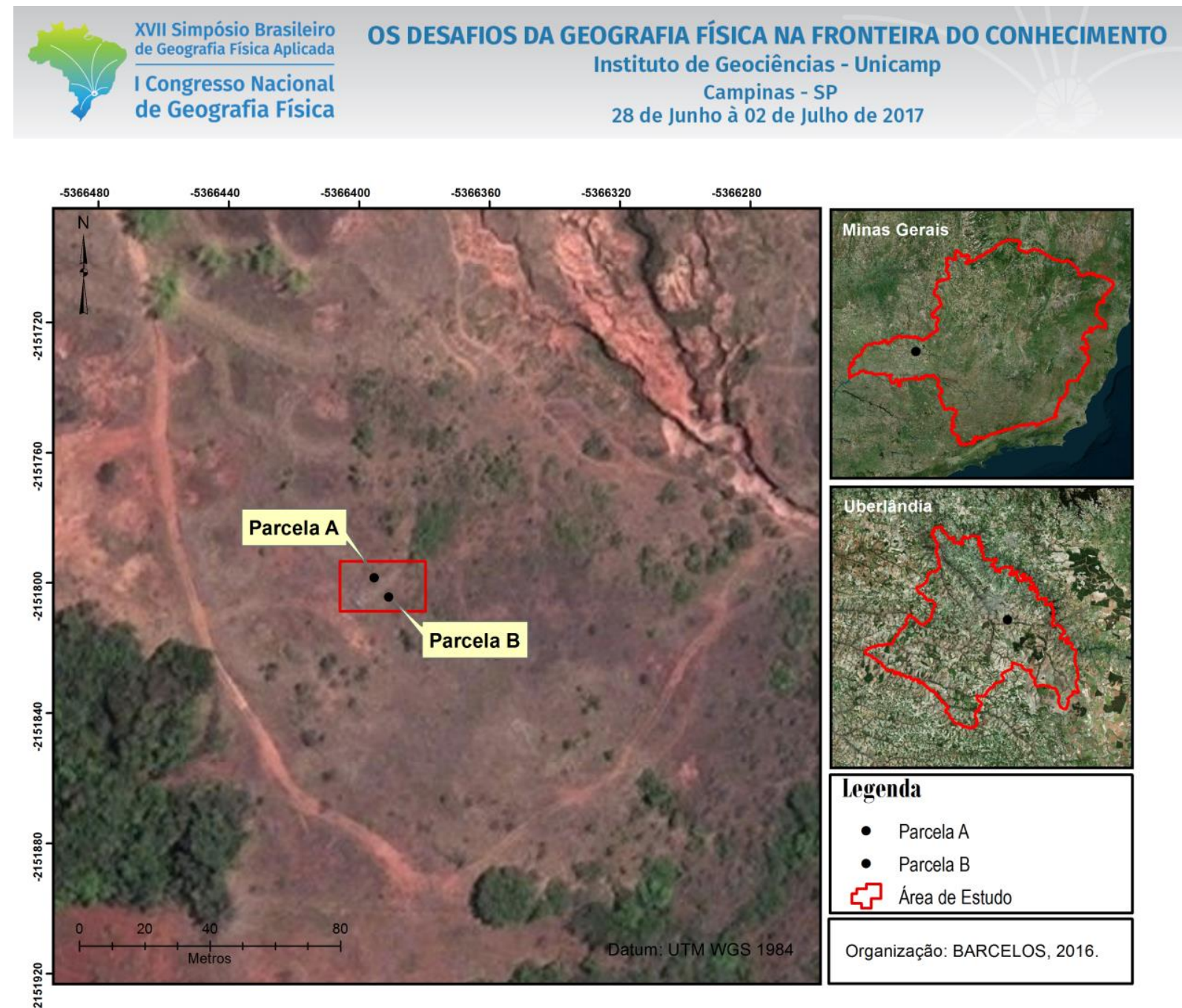

Figura 2: Localização das parcelas experimentais na área de estudo

Devemos levar em consideração que a área de estudo está passando por processo de recuperação devido o manejo inadequado no passado para retirada de cascalho, mas mesmo estando próxima a voçoroca presente na região tal ação erosiva não afeta as parcelas de modo a alterar os resultados.

Para o desenvolvimento da pesquisa foram definidos alguns parâmetros para contribuir com o monitoramento das parcelas, sendo esses, precipitação, escoamento superficial e produção de sedimento. Os dados adquiridos nas coletas semanais foram levados ao laboratório para serem quantificados e posteriormente analisados. A pesquisa foi dividida em duas etapas, a primeira etapa foi realizada no período de final de outubro de 2014 ao final de janeiro de 2015, período que apresentou significativos índices pluviométricos. A segunda etapa, a qual será exposta no presente artigo, estendeu-se de fevereiro a abril de 2015.

Deste modo, para que fosse possível realizar as coletas durante o período de análise foi necessária à manutenção das parcelas antes da primeira etapa do trabalho, sendo feita apenas uma limpeza do ambiente, retirando toda a brachiaria que havia se desenvolvimento naturalmente desde a última pesquisa 
no local. A limpeza foi realizada com objetivo de começar a trabalhar com as parcelas de monitoramento de erosão desde o estágio inicial, assim apresentando solo exposto em ambas as parcelas.

\subsubsection{Análise dos processos erosivos}

A quantificação do escoamento superficial, da produção de sedimento e da precipitação total semanal foi estabelecida a fim de compreender a evolução das alterações físicas no solo frente à ação dos processos erosivos. Para a obtenção dos dados referentes ao escoamento superficial foi necessária a coleta da água resultante da precipitação contida nos galões, onde inicialmente era homogeneizada, mensurava-se sua quantidade total retida na semana e coletava-se 2 litros de água para filtragem e realização do cálculo de perda de solo em laboratório.

Para filtragem das amostras seguiu-se etapas, sendo a pesagem dos papeis filtros em balança de precisão em temperatura ambiente de $25^{\circ} \mathrm{C}$, para evitar alterações nos resultados de pesagem antes e após a filtragem, eram feitas em horários próximos devido à diferença da pressão atmosférica em diferentes períodos do dia. No final da pesagem do filtro inicial com a filtragem da amostra era feito uma nova pesagem para obtenção do resultado final, onde era subtraído o peso final com o peso inicial de cada papel filtro, para obter a quantidade de sedimento encontrado em cada amostra.

Posteriormente a filtragem das amostras era somada nesta quantificação os sedimentos depositados através do escoamento superficial nas calhas coletoras, sendo possível a obtenção da perda de solo semanal e com o auxílio da estação pluviométrica instalada próxima às parcelas era factível adquirir valores de precipitação semanal total.

\section{Resultados e discussão}

Em conformidade com os resultados obtidos na primeira etapa do estudo foi possível dar continuidade a pesquisa. Neste trabalho trouxemos o resultado final do estudo, sendo enfatizada a segunda etapa que consistiu na realização das coletas finais dos parâmetros já estabelecidos na primeira etapa do trabalho como já mencionado anteriormente. As coletas foram realizadas nos meses de fevereiro a abril de 2015, os resultados obtidos mostram a relação entre o escoamento superficial, produção de sedimento e precipitação semanal de cada parcela. Observamos que logo após o período de chuva dos meses anteriores as coletas da segunda etapa, verificou-se crescimento vegetativo nas duas parcelas significativamente, descaracterizando as parcelas que posteriormente se apresentavam com solo exposto e supostamente selado (primeira etapa do estudo). 


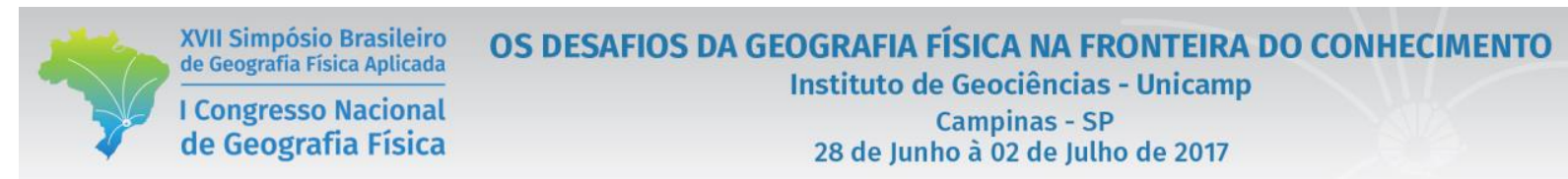

Segundo os resultados obtidos na primeira etapa desta pesquisa, observamos que a parcela A apresentava elevada taxa de escoamento superficial, devido ao selamento do solo e possivelmente pela falta de porosidade necessária para a infiltração da água da chuva, e na parcela B apresentou resultados próximos, mas com diferença na taxa de escoamento superficial que foi menor devido ao menor selamento do solo da parcela, mas com algumas mudanças nos resultados referentes aos dias de chuvas de grande intensidade acompanhada de solos já saturados (BARCELOS, 2016).

Na segunda etapa de coleta e análise obtivemos resultados inversos, onde a parcela A e B apresentaram escoamento superficial relativamente menor que nos meses anteriores devido à baixa precipitação associada ao desenvolvimento da cobertura vegetal (Figura 4). Houve também pouca produção de sedimento nas duas parcelas, passando de 50,41 kg nos primeiros meses de coleta para 1,94 kg de material erodido nos meses finais da coleta na parcela A, e na parcela B o mesmo foi constatado, alterando-se de $69,74 \mathrm{~kg}$ para $6,08 \mathrm{~kg}$ de material erodido.

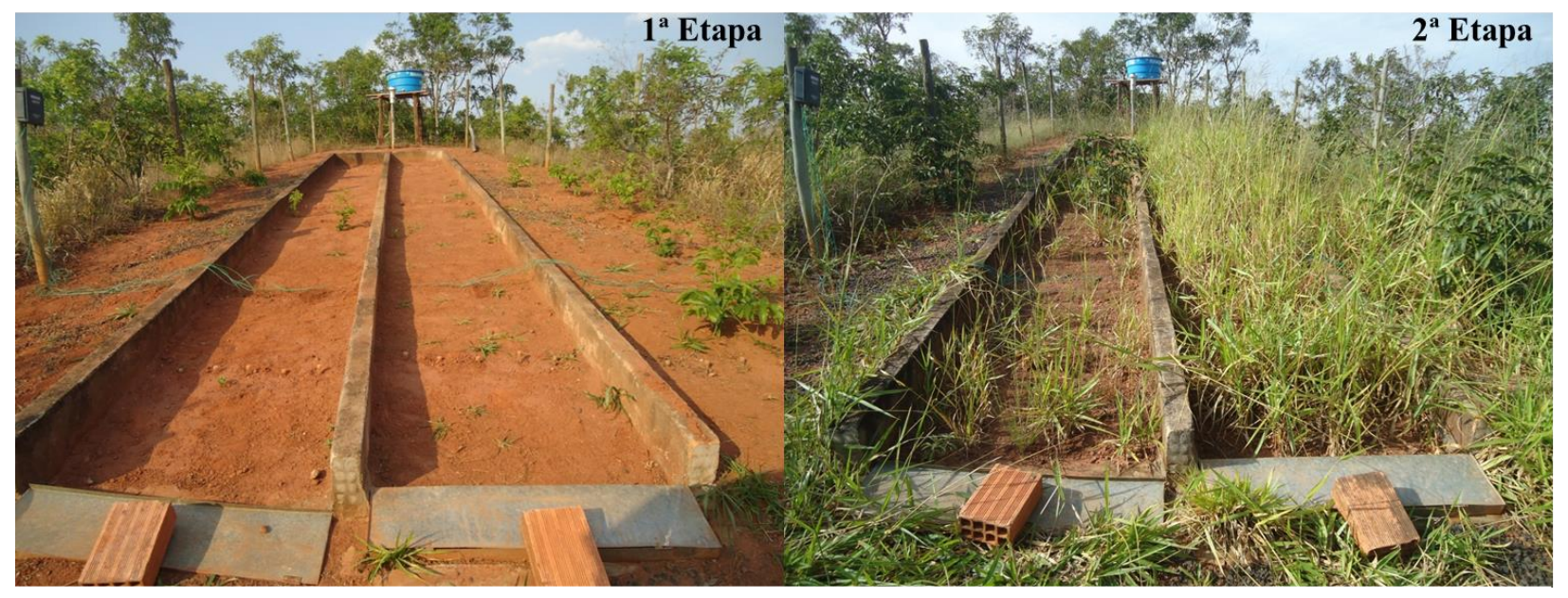

Figura 4: Parcelas experimentais $1^{\mathrm{a}}$ etapa e $2^{\mathrm{a}}$ etapa da pesquisa

Em relação à cobertura vegetal sabemos que o seu principal papel é proteger o solo contra a ação erosiva das gotas da chuva e da intensidade do escoamento superficial, além de favorecer o coeficiente de infiltração e o equilíbrio entre a infiltração e o escoamento, mas sua ação protetora irá divergir de acordo com cada espécie vegetativa, pois suas características são diferentes em relação à densidade de vegetação sobre o solo (MAFRA, 2012). Com isso, o escoamento superficial em ambas as parcelas seguiu uma variação comum de maneira geral, que está diretamente ligada à quantidade, intensidade e distribuição da precipitação semanal. Podemos ver no gráfico 1 os resultados das parcelas A e B quantificados semanalmente de acordo com os resultados de cada parâmetro. 


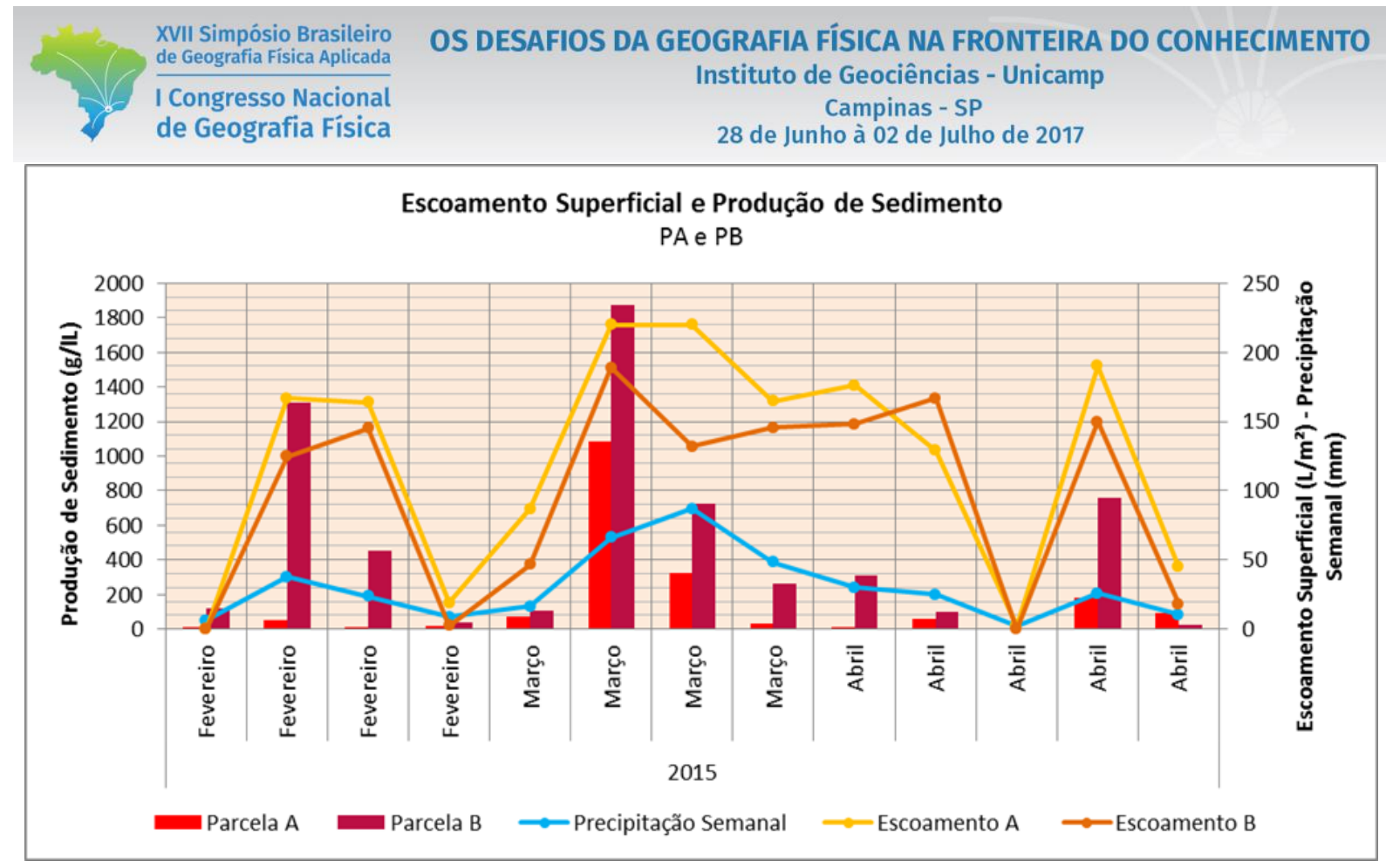

Gráfico 1: Escoamento superficial e produção de sedimento parcelas A e B

Na parcela A o escoamento superficial foi alto comparado ao da parcela B, pois provavelmente o solo da parcela A ainda se encontra selado, mas agora com a presença mínima da vegetação no interior da parcela seus resultados apresentaram um equilíbrio entre a precipitação, escoamento e produção de sedimento, sendo a parcela que apresentou menor perda de solo. Já na parcela B o escoamento superficial foi menor devido a grande concentração de cobertura vegetal presente no interior da parcela, porém em relação aos resultados de perda de solo não obtivemos um equilíbrio entre os parâmetros, devido à presença de cobertura vegetal em grande quantidade na parcela e das chuvas mal distribuídas durante as semanas, constatamos que as folhas das gramíneas possivelmente concentraram as gotas da água das chuvas que ao invés de desenvolver seu papel de proteção ao solo aumentou a capacidade erosiva.

Com exceção na semana de 22/04 a 29/04, os resultados referentes ao escoamento superficial e produção de sedimento foram inversos, pois a parcela A apresentou maior perda de solo do que na parcela B, devido à distribuição uniforme da chuva.

\section{Considerações Finais}

As parcelas experimentais monitoradas neste trabalho passaram por duas etapas de coleta e análise de seus parâmetros, a partir disso no período de seis meses foi possível obter resultados acerca do escoamento superficial, da produção de sedimento e da precipitação de cada semana, com isso foi possível comparar os resultados e conclui-se que o solo que se apresenta possivelmente selado está susceptível a sofrer 


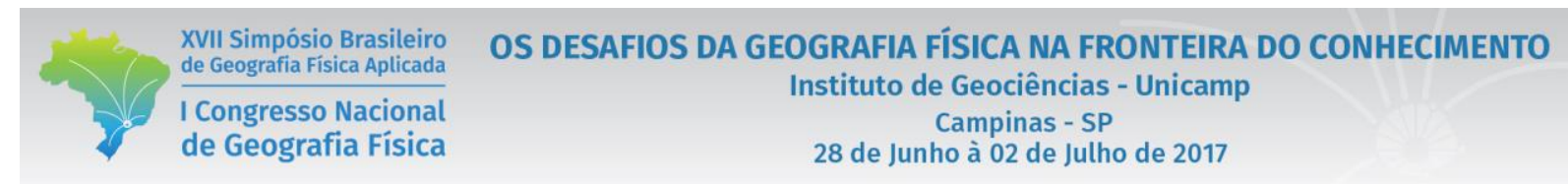

alterações em sua dinâmica hidrogeomorfológica, devido à baixa densidade de cobertura vegetal, da intensidade e da distribuição das chuvas que ocorrem no ambiente, mas quando ocorre o inverso dessa situação o solo fica parcialmente protegido contra a ação erosiva da chuva através da cobertura vegetal favorecendo a infiltração, a diminuição do escoamento superficial e da perda de solo.

Desta maneira, avalia-se que as perdas periódicas a partir dos processos erosivos originam-se a partir da transformação de cada ambiente, sendo influenciadas pelos fatores antrópicos em maior quantidade e ou pelas intempéries do clima. Apesar disso, o desempenho do solo frente a esses processos erosivos, requer uma visão mais detalhada, tendo em conta os fatores que auxiliam ou não para a evolução dos processos, por isso se faz necessário o monitoramento de parcelas de erosão em ambiente de cerrado, para identificar os aspectos próprios desse ambiente.

\section{Agradecimentos}

O presente trabalho foi realizado com apoio do CNPq, Conselho Nacional de Desenvolvimento Científico e Tecnológico, Bolsista do CNPq/ Brasil (CNPQ2015-HUM004), e ao CNPQ através do projeto PQ 302654/2015-1 pelo apoio a realização da pesquisa. Agradecemos também a FAPEMIG pelo apoio a participação no XVII SBGFA.

\section{Referências}

AB'SABER, A. N. Os domínios da natureza no Brasil: potencialidades paisagísticas. São Paulo: Ateliê Editorial, 2003. 159 p.

ALVES, R. A. Monitoramento dos Processos Erosivos e da Dinâmica Hidrológica e de Sedimento de uma Voçoroca: estudo de caso na Fazenda do Glória na zona rural de Uberlândia- MG. 2007. 104 f. Dissertação (Mestrado em Geografia), Instituto de Geografia, Universidade Federal de Uberlândia, Uberlândia, 2007.

BACCARO, C.A.D. Processos Erosivos no Domínio do Cerrado. In: GUERRA, A.J.T; SILVA, A.S; BOTELHO, R.G.M. (Orgs.). Erosão e Conservação dos Solos: Conceitos, Temas e Aplicações. Rio de Janeiro: Bertrand Brasil, 2007. p. 195-223.

BARCELOS, A.C.; QUEIROZ, J.S. Mensuração da perda de solo por erosão hídrica em ambiente de cerrado. In: XI Simpósio Nacional de Geomorfologia - SINAGEO, 11., 2016, Maringá, Anais eletrônicos... Maringá, 2016. Disponível em: <http://www.sinageo.org.br/2016/trabalhos/2/2-291-1565.html> Acesso em: 21 Fev. 2016.

BARRELLA, W. et al. As relações entre as matas ciliares os rios e os peixes. In: RODRIGUES, R.R.; LEITÃO FILHO; H.F. (Ed.). Matas ciliares: conservação e recuperação. 2.ed. São Paulo: Editora da Universidade de São Paulo, 2001.

BELTRAME, A. DA V. Diagnóstico do meio físico de bacias hidrográficas: modelo e aplicação. Florianópolis: Ed. da UFSC, 1994. 112 p. 
BEZERRA, J. F. R. Avaliação de geotexteis no controle da erosão superficial a partir de uma estação experimental, Fazenda do Glória - MG. 2006. 118 f. Dissertação (Mestrado em Geografia e Gestão do Território) Instituto de Geografia, Universidade Federal de Uberlândia, Uberlândia, 2006.

BIGARELLA, J. J. et al. Estrutura e origem das paisagens tropicais e subtropicais. Florianópolis: Ed. da UFSC, 2003. v.3. p. $877-1436$.

DECHEN, S. C. F. et al. Manejo de solos tropicais no Brasil. Reunião brasileira de manejo e conservação do solo e da água: manejo integrado a ciência do solo na produção de alimentos, 15. Santa Maria - RS. UFSM, 2004. p.1-25.

EMPRESA BRASILEIRA DE PESQUISA AGROPECUÁRIA. Práticas de conservação do solo e recuperação de áreas degradadas. Rio de Janeiro: Centro Nacional de Pesquisa dos Solos, 2003. 1 ed., 30p.

GUERRA, A.J.T. O início do processo erosivo. In: Guerra, A.J.T.; Silva, A.S. \& Botelho, R.G.M. (Org). Erosão e Conservação dos solos: conceitos, temas e aplicações. 1. ed. Rio de Janeiro: Bertrand Brasil, 1999. p. 1-50.

GUERRA, A. J.T. \& CUNHA, S.B. Geomorfologia e meio ambiente. Rio de Janeiro: Bertrand Brasil, 1966. 393 p.

GUERRA, A. J. T; CUNHA, S. B. Geomorfologia: uma atualização de bases e conceitos. $12^{\mathrm{a}}$ ed. Rio de Janeiro: Bertrand Brasil, 2013. 472 p.

GUERRA, A. T. \& GUERRA, A. J. T. Novo Dicionário Geológico-Geomorfológico. Bertrand Brasil, Rio de Janeiro, 1997, 648p.

GUERRA, A. J.T.; JORGE, M. do C. O. Geomorfologia do Cotidiano: A Degradação dos Solos. Revista GEONORTE, Edição Especial, V.4, N.4, p.116-135, 2012. Disponível em:

<http://www.revistageonorte.ufam.edu.br/ >. Acesso em: 14 Janeiro 2016.

KLINK, C. A.; MACHADO, R. B. (2005) A conservação do Cerrado brasileiro. Megadiversidade, Belo Horizonte, v. 1 , n. 1 , jul. 2005 , p. 148-155.

LEPSCH, I. F. Solos: formação e conservação. 4ª ed. São Paulo: Editora Melhoramentos, 1976. 158 p.

MACHADO, R.B.; RAMOS NETO, M.B.; PEREIRA, P.G.P.; CALDAS, E.F.; GONÇALVES, D.A.; SANTOS, N.S.; TABOR, K; STEININGER, M. (2004). Estimativas de perda da área do Cerrado brasileiro. Conservation Internacional, Brasília, $23 \mathrm{p}$.

MAFRA, N. M. C. Erosão e planificação de uso do solo. In: Guerra, A.J.T.; Silva, A.S. \& Botelho, R.G.M. (Org). Erosão e Conservação dos solos: conceitos, temas e aplicações. 7. ed. Rio de Janeiro: Bertrand Brasil, 2012. p. 301320 .

SANO, E. E. ; FERREIRA, L. G. (2005) Monitoramento semidetalhado (escala 1:250.000) de ocupação de solos do cerrado: considerações e proposta metodológica. In: XII Simpósio Brasileiro de Sensoriamento Remoto. Anais... Goiânia, INPE, 16-21 abril 2005, p. 3309-3316.

SHIKI, S. (1997). Sistema agroalimentar no Cerrado brasileiro: caminhando para o caos? In: SILVA, J. G.; SHIKI, S.; ORTEGA, A. C. (orgs) Agricultura, meio ambiente e sustentabilidade do Cerrado brasileiro. Uberlândia, UFU, $372 \mathrm{p}$.

THORNES, J.B. (1980). Erosional processes of running water and their spatial and temporal controls: a theoretical viewpoint. In Soil erosion. Editores: M.J.Kirkby e R.P.C. Morgan, 129-182 p. 